\section{SUN-SPOTS AND THE RAINFALL OF PARIS}

IN a paper on this subject by Mr. C. Meldrum, F.R.S., read at the Meteorological Society of Mauritius, after some preliminary remarks, the author said :-

The rainfall observations made at the Observatory of Paris formed perhaps the longest series on record. They were commenced in 1689, and, with the exception of twenty-six years, viz., 1697-98, 1755-72, and 1798-1803, they had been continued to the present day.

From 1689 to 1870 there had been, according to Dr. Rudolph Wolf and Prof. Fritz, seventeen years of maximum and seventeen years of minimum sunspot. Now it would be seen from the following table showing the years of maximum and minimum, and (as far as possible) the rainfall in each of them at the Paris Observatory, not only that more rain had fallen in the former than in the latter, but that throughout that long period there had, as far as could be ascertained, been only two exceptions to the rule that the maximum were wetter than the minimum years.

\begin{tabular}{|c|c|c|c|c|}
\hline Min. years. & Rainfall. & Max. years. & Rainfall. & Dif. \\
\hline 1689 & $\begin{array}{c}\mathrm{mm} . \\
5^{1} 3^{\circ} \mathrm{O}\end{array}$ & 1693 & $\begin{array}{c}\mathrm{mm} . \\
6 \mathrm{r} 35\end{array}$ & $\begin{array}{l}\text { mm. } \\
+\mathrm{I} 00.5\end{array}$ \\
\hline 1698 & & 1705 & $372 \cdot 7$ & $?$ \\
\hline 1712 & 573.3 & 1717 & $478 \cdot 8$ & -945 \\
\hline 1723 & $229^{\circ} 9$ & 1727 & $370^{\circ} 0$ & $+\mathrm{I} 40^{\circ} \mathrm{I}$ \\
\hline 1733 & $210^{\circ} 2$ & 1738 & $4 \mathrm{CO}^{\circ} \mathrm{O}$ & +189.8 \\
\hline 1745 & $337^{\circ} 3$ & $175^{\circ}$ & $5^{6} 4 \div 5$ & $+227 \cdot 2$ \\
\hline 1756 & $?$ & $176 \mathbf{1}$ & ? & ? \\
\hline 1766 & ? & $1770^{\circ}$ & $?$ & ? \\
\hline 1775 & $534^{\circ} 4$ & 1779 & $560^{\circ} I$ & +257 \\
\hline I 784 & $442 \cdot 5$ & 1789 & $500 * 2$ & $+57 \%$ \\
\hline 1798 & ? & 1804 & $703^{\circ} \mathrm{I}$ & $?$ \\
\hline 1810 & $437^{\circ} \mathrm{O}$ & 1816 & $545^{\circ} 6$ & +108.5 \\
\hline 1823 & $457^{\circ} \mathrm{O}$ & 1829 & 559.8 & +102.8 \\
\hline 1833 & $502 \cdot 9$ & 1837 & 547.5 & $+44^{\circ} 6$ \\
\hline 1843 & $542 \cdot 2$ & 1848 & $575^{\circ} 2$ & $+33^{\circ} \circ$ \\
\hline 1856 & 5653 & 1860 & 655.2 & $+89^{\circ} 9$ \\
\hline 1867 & $5^{6} 5^{\prime I}$ & $187^{\circ}$ & $417 \cdot 8$ & $-147^{\circ} 3$ \\
\hline
\end{tabular}

From the above table it followed:

1. That the mean rainfall of the thirteen minimum sunspot years in the second column was $454^{\circ} 6 \mathrm{~mm}$., and of the fifteen maximum years in the four th column $524^{\circ} 3 \mathrm{~mm}$., giving a mean annual excess of $69^{\circ} 7 \mathrm{~mm}$. in favour of the latter.

2. That the results in the fifth column, of direct comparisons of the rainfalls in thirteen minimum with the rainfalls in thirteen maximum years, gave a mean excess of $67.7 \mathrm{~mm}$. in favour of the latter.

3. That comparing the rainfall in each minimum year, from 1689, with that of the following maximum year, there were.only two minimum years (1712 and 1867 ) in which the rainfall had not been less than in the maximum year.

4. That comparing the rainfall in each maximum year, from 1693, with the rainfall in the following minimum year, there was, as far as was known, only one maximum year (1705) in which the rainfall was not greater than in the minimum year.

5. That, as a rule, therefore, the rainfall of a maximum sunspot year was greater than that of either the preceding or following minimum year; a circumstance which seemed to indicate a tendency, at least, to a periodic variation in the rainfall of Paris.

The most important feature was, not that on the whole the rainfall of the maximum had exceeded that of the minimum years, but that the excess had occurred in eleven out of thirteen cases. This frequent repetition of the same phenomenon pointed to a periodicity. A mere excess of rainfall in the maximum years, as a whole, could not have done so; for such an excess might have happened if only a much smaller number of the maximum years had been wetter than the preceding or following minimum years. But that was not the case. From 1723 down to 1867 there was not, as far as the observations went, an instance in which the rainfall of a maximum year did not exceed that of the previous and next minimum year.

To the possible objection that the years of maximum and minimum sun-spots of the seventeenth and eighteenth centuries had probably not been so well determine I as those of the nineteenth century, it could be replied that the results for the nine- teenth century, also, showed that the rainfall had been greater in the maximum than in the minimum years. From 1804 to 1867 there had been six maximum and six minimum years. Now in every case the rainfall of the former exceeded that of the latter, and the mean excess was $86.1 \mathrm{~mm}$.

Since 1867 there had been only one maximum year, viz., 1870, and the next minimum year was not yet known. It was true that the rainfall of Paris in 1870 had been comparatively small, and it was not improbable that it would be less than that of the next minimum year; but if such should be the case it would be the only exception to the general rule since the commencement of the century, if not since 1705 .

The total rainfall at the Paris Observatory in the seven maximum years, since 1800 , was $4,004.2 \mathrm{~mm}$, and in the six minimum years $3,069^{\circ} 5 \mathrm{~mm}$. A rainfall of $934^{\circ} 7 \mathrm{~mm}$., therefore, would be required in the seventh minimum year to restore the balance; and there was very little chance of this, the greatest recorded rainfall, since the observations had been commenced, having been $703^{\circ} \mathrm{I} \mathrm{mm}$. in the maximum year $\mathrm{I} 804$, and the least $21^{\circ} 2 \mathrm{~mm}$. in the minimum year 1733

The average duration of the sun-spot cycles was, according to Wolf, I I'I years. The last five complete cycles, starting from a minimum year, were from I810 to 1867 . Taking in each of these cycles the three years iof most and the three years of fewest spots, and comparing the rainfall of Paris in the former triennial periods with that in the latter, it was found that the rainfall in each minimum period was less than that in the following maximum period. The figures were as follows :-

\begin{tabular}{|c|c|c|c|}
\hline Minimum periods. & Rainfall. & Maximum periods. & Raisfall. \\
\hline $\begin{array}{l}1810-12 \\
1822-24 \\
1832-34 \\
1842-44 \\
1854-56 \\
1865-67\end{array}$ & $\begin{array}{l}\text { mm. } \\
153 \mathrm{I}^{\circ} \cdot 5 \\
1453 \cdot 2 \\
1380 \cdot 1 \\
1455 \cdot 3 \\
1522 \cdot 8 \\
1751 \cdot 7\end{array}$ & $\begin{array}{l}1815-17 \\
1828-30 \\
1836-38 \\
1847-49 \\
1859-60 \\
1870-72\end{array}$ & $\begin{array}{c}\mathrm{mm} . \\
\mathrm{I} 56 \mathrm{r} \cdot 4 \\
\mathrm{I} 7 \mathrm{r} 8 \cdot 2 \\
\mathrm{I} 700 \cdot 0 \\
\mathrm{I} 602 \cdot 7 \\
\mathrm{I} 658 \cdot 7 \\
1628.5\end{array}$ \\
\hline
\end{tabular}

It would be seen, however, that the rainfall in the minimum period $1865-67$ exceeded that in the maximum period $1870-72$ of the cycle which had commenced in 1867 (and the end of which was not yet fully known), the rainfall of 1866 having been abnormally great. But as the rainfall in the three years I $871-73$ (I817.9 mm.) when the sun-spots were still numerous, had exceeded that in the three years 1865.67 , the usual excess in the maximum periods may have only been somewhat retarded.

By forming, in the manner described on previous occasions, a mean cycle out of the five cycles from 1810 to 1867 , and com. paring the rainfall of Paris with the sun-spots for each year, the following mean results were obtained :-

\begin{tabular}{c|c|c}
\hline Years of mean cycle. & Rain variation. & Spot variation \\
\hline & mrn. & -32.3 \\
2 & -2.3 & -19.2 \\
3 & -20.3 & -1.1 \\
4 & -22.2 & +30.2 \\
5 & +15.3 & +40.0 \\
6 & +47.5 & -29.8 \\
7 & +40.0 & +11.3 \\
8 & +12.6 & -12.2 \\
9 & -17.0 & -12.8 \\
10 & -23.3 & -21.1 \\
11 & +2.0 & -23.6
\end{tabular}

The above table showed that both the spots and the rain were above $(+)$ or below $(-)$ their respective averages in the same years of the mean cycle, except the last, and that they both attained their maximum in the same year, namely, the fifth. The discrepancy, with respect to sign, in the eleventh year, was owing to the years 1854 and 1866 having been abnormally wet.

From the maximum year 1816 to the maximum year 1870 there had also been five complete cycles, which, omitting fractions, gave the following rasults :- 


\begin{tabular}{c|c|c}
\hline Eears of mean cycle. & Rain variation. & Spot variation. \\
\cline { 2 - 3 } I & mm. & \\
2 & +20 & +23 \\
3 & +14 & +14 \\
4 & +5 & +5 \\
5 & -10 & -6 \\
6 & -10 & -19 \\
7 & -19 & -37 \\
8 & -9 & -25 \\
9 & -1 & +2 \\
IO & -2 & +31 \\
II & -1 & +45
\end{tabular}

Although in both tables the rainfall variation was not so regular as the sun-spot variation, yet there was a remarkable parallelism. At all events, both tables showed that the rainfall was greatest when the spots were most numerous, and on the whole, least when they were fewest.

From the several results now obtained it was concluded that any relation that might subsist between the rainfall of Paris and sun-spots was direct, instead of inverse, and that excessive rainfall in the present minimum period, or year, would be merely an exception to the general rule.

M. Flammarion was careful to state that the recent wet weather and paucity of sun-spots might have been only a coincidence. Were the far more frequent cases (during nearly two centuries) of comparatively wet years and seasons when solar maculation was greatest, and of comparatively dry years and seasons when it was least, also mere coincidences? Various considerations had led to the conclusion that they were not.

The circumstance that the sun's physical state, as indicated by the changes that took place in and above the photosphere, was subject to periodic variations, afforded ground for supposing that corresponding variations took place on and near the earth's surface. As a matter of fact, it was now universally admitted, although long contested, that terrestrial magnetism and auroras were subject to variations corresponding directly with those of the sun. Would it, then, as M. Flammarion had asked, ke at all surprising to find that meteorological phenomena were subject to similar variations?

Supposing it were fully proved that the rainfall of the whole globe varied directly as the amount of sun-spots, it could not be expected that the law would invariably hold good everywhere. At any given place there were exceptions to every meteorological cycle. For example, on an average, the diurnal temperature increased from near sunrise to an hour or two after noon, and then decreased; but in many parts of the world there were frequent exceptions, and these were so great that the coldest and warmest hours might respectively occur at any time of the day or night. Yet there was a daily cycle of temperature corresponding with the position of the sun. Again, there was a diurnal oscillation of the atmospheric pressure, which, within the tropics, was very regular, though now and then disturbed or entirely masked, but which, in many extra-tropical countries, could not be determined except by taking means of hourly observations carried on for many days. Hourly barometric observations made on ten or more successive days, or cycles, in high latitudes, might not show a trace of the mean diurnal oscillation, which nevertheless existed.

It could not be said, then, that because the rainfall of a place did not invariably increase and decrease as the sun-spots did, there was no rainfall cycle crresponding with the sun-spot cycle. On the contrary, considering the capriciousness of the climate of Paris, it was somewhat surprising that a mean of the rainfall for only five cycles gave such results. There were many five consecutive days on which hourly observations would not give more favourable results for determining the daily march of the pressure of the atmosphere. But while there were 365 cycles of the diurnal oscillation of the barometer in one year, the same number of eleven-year rainfall cycles, if such cycles existed, extended over 4,05 I years; so that it was easier to discover the former than the latter by observations at a single station. If the rainfall of Paris and the sun-spots had been observed and compared for as many sun-spot cycles as there were cycles of the diurnal oscillation of the barometer in one year, an eleven-year cycle of the rainfall might now be as well established as the diurnal cycle of the atmospheric pressure or the diurnal cycle of the temperature of the air. But the number of sun-spot cycles during which observations of the rainfall had as yet been made were few. Was it necessary, then, to wait thousands of years before it could be known whether or not there was an eleven-year rainfall cycle? It was believed that such was not the case. The problem might be solved in a much shorter time.

If the total annual precipitation over the whole globe were accurately known for eleven years, and if it were found that it was not a constant quantity, but increased from a minimum in the first year to a maximum in the fourth or fifth, and then decreased to a minimum in the eleventh, there would be a strong probability that this variation was due to some cause operating from without, and that that cause resided in the sun. For to what could such a phenomenon be attributed but to a variation in the action of the great central luminary upon which the production and condensation of aqueous vapour depended? And if continued observation of the total precipitation over the globe showed repetitions of the same variation during several periods of which the mean length was about eleven years, it would be somewhat difficult to avoid the conclusion that the sun's radiant energy was subject to a corresponding variation, even if no trace of such variation had as yet been discovered.

Suppose, now, that in the course of time it were found that there was a periodic variation of the physical state of the sun, and that this variation had the same duration and characteristics as the previously known variation in the amount of aqueous pre. cipitation, would it not be concluded that the latter,variation was intimately connected with the solar variation, although the nature of the connection might be a mystery?

Similarly, it might be argued that if the sun, upon which aqueous precipitation depended, was subject to variation, precipitation would be subject to a corresponding variation.

Since, then, it was an established fact that the sun, as shown by a periodic increase and decrease of spots, faculæ, and eruptions, extending over a period of about eleven years, was subject to variation, it might reasonably be inferred that there was a similar variation in aqueous precipitation. And if actual measurements of the total annual amount of precipitation over the globe during one sun-spot cycle showed a variation similar in every respect to the solar variation, it would be concluded, not only that there was a rainfall variation, but that probably it was intimately connected with the sun-spot variation.

Theoretically, then, the object should be to ascertain the annual rainfall of the globe. If this could be done for a few sun-spot cycles, the question of a corresponding rainfall cycle would be settled. But the total annual precipitation could not be ascertained; for, in addition to other obstacles, some parts of the earth's surface were inaccessible.

It was more than probable, however, that, supposing a rainfall cycle existed, observations made at numerous points, in both hemispheres, would detect it in a comparatively short time. If, for example, in the course of a few sun-spot cycles, the rainfall in many remote parts of the world, and under every variety of climate, afforded strong evidence of corresponding cycles, if the evidence became stronger as the number] of observing stations increased, and if a mean of all the results showed a rainfall variation closely agreeing with the sun-spot variation, it would be difficult to resist the conclusion that the rainfall had a periodicity connected in some way or other with the solar periodicity.

Now, taking only the four sun-spot cycles from 1824 to 1867 , so as to avoid objections to earlier observations, it had been found, as shown at former meetings of the society, not only that the rainfalls of the British Islands, the Continent of Europe, America, India, Mauritius, the Cape, and Australia, had, as far as could be ascertained, been greatest when the sun-spots were most numerous, and vice versi, but that a mean of all the observations taken at 138 stations gave the following results, when compared with the sun-spots for the same four cycles :

\begin{tabular}{c|c|c}
\hline Years of mean cycle. & Rainfall variation. & Spot variation. \\
\hline & in. & -38.2 \\
I & -2.0 & -22.7 \\
2 & -0.9 & +5.7 \\
3 & +0.8 & +33.3 \\
4 & +1.9 & +41.9 \\
5 & +1.9 & +30.7 \\
6 & +1.8 & +13.1 \\
7 & +1.1 & -1.5 \\
8 & +0.2 & -12.1 \\
9 & -0.5 & -21.7 \\
10 & -0.8 & -28.0 \\
II & -2.0 &
\end{tabular}


The above table showed that the rainfall and sun-spots were, with a single exception, both below or above their respective means in the same years, and it would be seen that as the one increased or decreased, so did the other.

The separate results for Europe, America, India, and the stations in the Southern Hemisphere were similar. Those for Europe, for example, derived from observations taken at ninety nine stations, were as follows :

\begin{tabular}{c|c|c}
\hline Years of mean cycle. & Rain variation. & Spot variation. \\
\hline & in. & \\
\hline & -0.7 & -37.2 \\
3 & -1.7 & -22.8 \\
4 & -0.6 & +4.4 \\
5 & +0.8 & +33.0 \\
6 & +1.2 & +43.8 \\
7 & +1.8 & +32.9 \\
8 & +1.7 & +14.3 \\
9 & +1.4 & -16.6 \\
10 & -0.3 & -24.7 \\
11 & -1.1 & -24.0
\end{tabular}

Similar results were obtained by taking the sun-spot cycles separately. Those for the cuele $1856-67$, were as follows :-

\begin{tabular}{c|c|c}
\hline Years of.crcle. & Rain variation. & Spor variation. \\
\hline & in. & \\
\hline 2 & -2.2 & $-39^{\circ} 7$ \\
3 & -1.8 & $-39^{\circ} 9$ \\
4 & -0.8 & $+16^{\circ} 9$ \\
5 & +0.9 & $+24^{\circ} 3$ \\
6 & +1.9 & $+57^{\circ} .6$ \\
7 & +2.5 & $+38^{\circ}$ \\
8 & +2.0 & +12.4 \\
9 & +0.6 & -13.9 \\
10 & +1.0 & $-34^{\circ} 1$ \\
11 & -1.5 & $-45^{\circ}$.
\end{tabular}

The observations at many single stations, when treated by themselves, gave similar results. Those for Edinburgh and Bombay from 1824 to 1867 , and for the Cape of Good Hope from 1843 to 1867 , were as follows :-

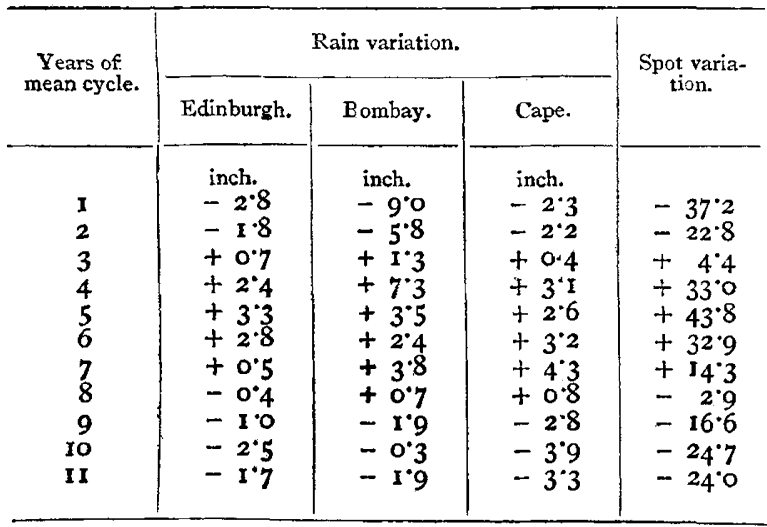

It had also been found that the levels of the principal rivers of Europe, and those of the great American lakes, had on the whole varied with the amount of sun-spots.

Such were a few of the results for the four sun-spot cycles from 1824 to 1867 . Now it was important to remark that the evidence had increased as the rainfall observations had increased. Hence, with the large number of observing stations now spread over the world, it was inferred that a few more sun-spot cycles would settle the question of a corresponding rainfall cycle, if it was not settled already.

Another way of testing the matter in a comparatively short time was to compare, as far as possible, the daily, weekly, or monthly rainfall of the globe with the sun's-spotted area; for the amount of sun-spots varied much in the course of a year.

The results for the sun-spot cycle which commenced in 1867 , and which probably was now closing, were not yet fully known, but there was reason to believe that they would be similar to those obtained for former cycles. It could already be stated that a mean of a large number of observations made in all parts of the world showed that the rainfall in the years I 870-72 had been greater than that in the ycars $1865-67$, and judging from the severe droughts that had occurred in India, China, Japan, Australia, South Africa, South America, \&c., since 1876 , it was not improbable that the rainfall of the last three years had been less than that of the years $1870-72$. In 1877 and 1878 the Nile, at Cairo, was lower than it had been for many years, showing that in the regions drained by it there had been a deficiency of rain. There had also of late years been a gradual decrease in the depth of water in the upper portions of the Amazon, so that navigation had sometimes been impeded, and this was supposed to be due to a general diminution of rainfall in the interior of South America. Moreover, various parts of the United States had lately been suffering from drought.

It would appear, then, that the circumstance that the rainfall of Paris had for a long period been greater in the years of maximum than of minimum sun-spots, was not a mere coincidence, but the result of a general law, and a similar remark. applied to the rainfalls of many other public observatories,

There were, as might be expected in the case of so fickle an element as the rain, great local exceptions to the general law, though not greater or more frequent than exceptions to the general laws of other cycles; but, as far as had yet been ascer tained, the rainfall of the globe varied directly as the sun-spots varied, the deficiency at some places in the maximum years being more than made up by the excess at others, and the excess in the minimum years reduced by a proportionately greater deficiency elsewhere.

Great fluctuations occurred near the epochs of maximum and minimum, but at a large majority of stations the rainfall in the three years of most sun-spots was almost invariably greater than that in the three years of fewest sun-spots.

The general rainfall cycle for the whole globe might be conceived to be made up of a number of local cycles differing more or less among themselves and from the general cycle, according to local conditions, and in some places the general cycle might be reversed.

From this point of view, it was possible that, although the recent rainy weather in Western Europe, at a time when there were few or no sun-spots, was a deviation from the general law, yet it was not an exception to the particular modification of it which prevailed in that part of the world. As a matter of fact, the rainfall of Western Europe was considerably above the average in $1844^{-} 45,1845-55$, and $1866-67$, that is at intervals the mean length of which was eleven years, and at times when there were few sun-spots. But Western Europe was only a small part of the earth's surface ; and from such a deviation, it could not be inferred that the rainfall, generally, was above the average in the minimum years.

In Mauritius there had been continuous observations only since 1852 . Since that time the rainfall had on the whole been considerably less in the minimum than in the maximum years, but it would take some time to eliminate the effects of local causes.

\section{SCIENTIFIC SERIALS}

Zeitschrift für wissenschaftliche Zoologic, $33 \mathrm{Bd}$., I and 2 Heft, October 29, with seventeen plates.-F. E. Schulze, researches upon the structure and the development of the sponges; eighth notice.-.. On the genus Hircinia of Nardo, and on Oligoceras, a new genus, Plates I to 4 . The genus of Nardo equals Stematumenia of Bowerbank; Sarcotragus, O. Schmidt ; Filifera, Lieberkiuhn; and Polytherses of Duchassaing and Michelotti. The structure of the filaments-algæe of some authors-is fully discussed. The new genus Oligoceras is established for a new species (collective) from Lesina, which, though a fibrous sponge, is almost destitute of fibrous material - Prof. E. Selenka, on the germ lamellæ and the arrangement of the organs in the Echinidx, Plates 5 and 7.-Prof. A. Weismann, Contributions to the natural history of the Daphnidæ, No. 6 and 7 , with Plates 8 to 13 .-Prof. P. Langerhans, on the worm fauna of Madeira, with Plates 14 to I7. 